\title{
Antibiotic Sensitivity to Helicobacter pylori Growth
}

\section{Haitham Refaay Mustafa Elshiekh ${ }^{1 *}$, Amr Mohamed Hassan Elrabat ${ }^{2}$, Abd EL Mohsen E. EL desoky ${ }^{3}$ and Mahmoud Mohammed Zaky}

\author{
${ }^{1}$ Department of Microbiology, Faculty of Science, Al-Azhar University, Assiut, Egypt \\ ${ }^{2}$ Faculty of Medicine, Mansoura University, Egypt \\ ${ }^{3}$ Internal Medicine Department, Hepatogastroenterology Unit, Mansoura Specialized Medical \\ Hospital Mansoura University, Egypt \\ ${ }^{4}$ Department of Microbiology, Faculty of Science, Port Said University, Egypt \\ *Corresponding author
}

\begin{tabular}{l} 
Ke y w or d s \\
$\begin{array}{l}\text { Helicobacter pylori } \\
\text { growth, Antibiotic } \\
\text { sensitivity. }\end{array}$ \\
\hline Article Info \\
$\begin{array}{l}\text { Accepted: } \\
28 \text { October } 2017 \\
\text { Available Online: } \\
10 \text { December } 2017\end{array}$ \\
\hline
\end{tabular}

10 December 2017

\section{A B S T R A C T}

A combination of different antibiotics was mostly used in $\mathrm{H}$ pylori eradication. Eradication of $\mathrm{H}$. pylori likely has a beneficial effect in preventing the development of subsequent gastric dysplasia,a premalignant lesion of gastric Ulcer. This study comprised fifty gastritis peptic ulcers patients, 24 of them were males and 26 were females. These patients were attending the gastroscope clinic at Gastroenterology center (GEC), Mansoura University Hospitals (MUHs), over 6 months, during the period from May 2015 to April 2016, with symptoms and signs suggesting gastritis. H pylori response to both Clarithromycin and Metronidazole antibiotic sensitivity was giving the same figures. In respect to gender, $90.9 \%$ of males and $88.2 \%$ of females were sensitive to both antibiotics. Tetracycline antibiotic sensitivity was showing that $81.8 \%$ of the males and $88.2 \%$ of the females were sensitive to Tetracycline antibiotics. H pylori response to both Clarithromycin and Metronidazole antibiotic sensitivity was giving the same figures. In respect to gender, $90.9 \%$ of males and $88.2 \%$ of females were sensitive to both antibiotics. Tetracycline antibiotic sensitivity was showing that $81.8 \%$ of the males and $88.2 \%$ of the females were sensitive to Tetracycline antibiotics.

\section{Introduction}

\section{Helicobacter pylori Infection}

Helicobacter is a genus of Gram negative bacteria possessing a characteristic helicalshape. They were initially considered to be members of the Campylobacter genus, but in 1989 Goodwin et al., published sufficient reasons to justify his new genus name of Helicobacter. The Helicobacter genus contains about 35 species (Boyanova, 2011).
Some species have been found living in the lining of the upper gastrointestinal tract, as well as the liver of mammals and some birds. The most widely known species of the genus is $H$. pylori, which infects up to $50 \%$ of the human population (Yamaoka, 2008). The genus Helicobacter belongs to the Epsilon subdivision of the Proteobacteria, order Campylobacterales, family Helicobacteraceae (Fox, 2002). 
H. pylori is a helix-shaped (classified as a curved rod, not spirochaete) Gram-negative bacterium about $3 \mu \mathrm{m}$ long with a diameter of about $0.5 \mu \mathrm{m}$. It is microaerophilic; that is, it contains a hydrogenase which can be used to obtain energy by oxidizing molecular hydrogen $\left(\mathrm{H}_{2}\right)$ produced by intestinal bacteria (Olson and Maier, 2002).

It is motile by means of 2-6 sheathed unipolar flagellae; about $3 \mathrm{~m}$ long with a bulb at the end (O'Toole et al., 2000). Unlike most enteric bacteria, $H$. pylori lacks fimbrial adhesions. Its cell envelope consists of an outer and inner plasma membranes separated by a $30 \mathrm{~nm}$ thick periplasm. The dense cytoplasm contains nucleoid material, ribosomes and intracellular polyphosphate granules (Costa et al., 2013).

Helicobacter pylori are recognized as the major cause of gastritis, peptic ulcer, and gastric cancer in humans. The majority of bacteria in the gastric mucosal layer are spiral, but in unfavorable conditions, $H$. pylorican convert to coccoid form. Morphological changes are responses to physical and chemical stresses such as increased oxygen tension, $\mathrm{pH}$ changes, extended in vitro incubation, and exposure to antibiotics (Nilsson et al., 2002; Hosseini et al., 2012). H. pylori should be cultured as soon as possible after sampling because itis very delicate. Biopsies should be kept in a suitable transport medium for up to $24 \mathrm{~h}$ at 4 C. Once isolated, H. pylori can be stored

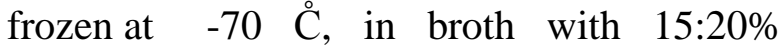
glycerol. Many types of medium are available for $H$. pylori culture, including selective agars (e.g., Pylori-agar, Wang media, Skirrow agar, and others), which contain specific antibiotics that inhibit commensal bacteria, and nonselective agars (e.g. Columbia blood agar, blood agar, and others). Cultures are incubated under microaerobic conditions $\left(85 \% \mathrm{~N} 2,10 \% \mathrm{CO}_{2}, 5 \% \mathrm{O}_{2}\right)$ at 35 to $37^{\circ} \mathrm{C}$ for at least $7 \mathrm{~d}$ before discarding cultures as negative. Morphological characteristics and positive catalase, oxidase, and urease reactions are used for identification of $H$. pylori (Martínez et al., 2016).

\section{H. pylori and hypoacidity/ anacidity}

During the early phases of oxyntic gastritis caused by $H$. pylori, gastric acid secretion may be only moderately reduced and $H$. pylori eradication even in patients with some degree of atrophy can augment acid secretion (Tie et al., 2016). In patients with pangastritis and oxyntic atrophy, H. pylori may not be detectable. It is presumed that $H$. pylori cannot live under these conditions. $H$. pylori may have been replaced by other microorganisms which can live in this situation in the stomach, or alternatively, NH3 production by $H$. pylori urease creates a local milieu too alkaline for the agent itself in a stomach without acid (de Medina et al., 2014). The role of acid for $H$. pylori to thrive is also demonstrated by the effects of acid inhibition in combination with antibiotics in eradication of $H$. pylori, as well as the possible oral spread in the stomach during treatment with inhibitors of gastric acid secretion. Interestingly, the new inhibitor of gastric acid secretion, vonoprazan, belonging to potassium-competitive acid blockers, and probably more efficient in inhibiting acid secretion than proton-pump blockers, seems to be more efficient in combination with antibiotics in eradicating $H$. pylori compared with proton-pump inhibitors (Murakami et al., 2016).

H. pylori infection is dependent on temporal hypoacidity or anacidity for its primary infection, but acidity to survive for a long time. $\mathrm{H}$ pylori infection in the antral mucosa causes duodenal ulcers induced by increased gastric acid secretion secondary to slight increased gastrin release from the $G$ cells, 
probably due to $\mathrm{NH} 3$ production provoked by urease (Helge et al., 2016). When infecting the oxyntic mucosa causing inflammation, the functions (mucous and $\mathrm{HCO} 3-$ production) of the superficial cells are reduced, predisposing for gastric peptic ulcer. Long-term infection of the oxyntic mucosa causes atrophy and marked reduced gastric acid secretion, leading to gastric hypoacidity and marked hypergastrinemia that probably predisposes for gastric cancer. $H$. pylori do not survive in a too acidic (patients with gastrinoma) or in an anacidic stomach (Scott et al., 1998). The interactions between $H$. pylori and the stomach are very complex, but the pathogenesis of most of the diseases in the stomach and duodenum have somewhat be understood, since $H$. pylori plays a central role in most of these conditions.

\section{Antigenic structure and cell wall}

\section{Outer Membrane Proteins}

The outer membrane protein (OMP) profile of $H$. pylori strains differs significantly from that of other Gram-negative species as no major OMPs predominate, rather multiple lowerabundance OMPs are observed. Approximately $4 \%$ of the $H$. pylori genome encodes an extraordinary large set of OMPs ( 64 OMPs) divided into five paralogous gene families and this unusual set of OMPs may be a reflection of the adaptation of $H$. pylori to the unique gastric environment where it is found (Alm et al., 2000).

\section{Lipopolysaccharide (LPS)}

LPS is the major component of the bacterial cell wall of Gram-negative bacteria. It is an organic compound found in the outer leaflet of outer membranes which contributes to the structural integrity of the bacteria and protects the membrane. Similar to other Gramnegative bacteria, the LPS of $H$. pylori is essential for the bacteria's survival. The LPS of $H$. pylori consists of an $\mathrm{O}$-specific polysaccharide chain, a core oligosaccharide, and a lipid part called lipid A, embedded in the outer membrane. While LPS is often highly toxic for the host, that of $H$. pylori is low in activation of the host immunological responses (Muotiala et al., 1992). Since they undergo phase variation and antigenic variation within a single strain, this would provide the bacteria with a dynamic adherent phenotype (Edwards et al., 2000).

The main aim of this study includes Calculated and statically analyzed for different antibiotic were used to test $H$ pylori response, they were Clarithromycin, Metronidazole, Tetracycline, Amoxicillin and Furazolidone.

\section{Materials and Methods}

\section{Subjects}

This study comprised fifty gastritis peptic ulcers patients, 24 of them were males and 26 were females. The mean age and standard error were $39.7 \pm 2.1$ (range: 16- 73). These patients were attending the gastroscope clinic at Gastroenterology center (GEC), Mansoura University Hospitals (MUHs), over 6 months, during the period from May 2015 to April 2016, with symptoms and signs suggesting gastritis.

\section{Gastric biopsy specimens}

During endoscopy using Olympus gastroscope (Q20 or Q200, Olympus, Tokyo), six antral biopsy specimens were obtained from adjacent areas of the gastric antrum with Olympus biopsy forceps FB- 24KR (Cap size, $6 \mathrm{~mm}$.). Two specimens directly dipped in 1 $\mathrm{ml}$ brain heart infusion broth in a sterile screw capped bottle for microbiological study. 


\section{Culture}

Two drops of homogenate were inoculated onto agar plate of Dent's medium (Selective medium) and another 2 drops were inoculated onto an agar plate of Chocolate medium (nonselective medium), incubated at $37^{\circ} \mathrm{C}$ under microaerophilic conditions (Campy pale systems, BBL, Cockeysville, Maryland, USA) for up to 5 days, (Kist., 2006).

\section{Results and Discussion}

\section{Antibiotic sensitivity to $H$. pylori growth}

Different antibiotic were used to test $H$ pylori response, they were Clarithromycin, Metronidazole, Tetracycline, Amoxicillin and Furazolidone.

Cross tabulation between positive gastritis patients to $H$. pylori organism gender and Clarithromycin antibiotic sensitivity with risk estimate between males and females was shown in (Table 1). Cross tabulation between positive gastritis patients to $H$. pylori organism gender and Metronidazole antibiotic sensitivity with risk estimate between males and females was shown in (Table 2). In respect to gender, $90.9 \%$ of males were sensitive to both antibiotics and $9.1 \%$ of them were resistance to the same antibiotics, $88.24 \%$ of females were sensitive with both antibiotics and $11.8 \%$ of them were resistant to the same antibiotics. In respect to the antibiotic sensitivity itself of both antibiotics, $40 \%$ of the sensitive were males and $60 \%$ of them were females. While, $33.3 \%$ of the resistant were males and $66.7 \%$ of them were females,

Cross tabulation between positive gastritis patients to $H$. pylori organism gender and Tetracycline antibiotic sensitivity with risk estimate between males and females was shown in (Table 3). In respect to gender,
$81.8 \%$ of the males were sensitive to Tetracycline antibiotics and $18.2 \%$ of them were resistant. Where, $88.2 \%$ of the females were sensitive to Tetracycline and $11.8 \%$ of them were resistant. In respect to the Tetracycline antibiotic sensitivity itself, 50\% of the resistant to Tetracycline were males and $50 \%$ of them were females. While, $37.5 \%$ of the sensitive to Tetracycline were males and $62.5 \%$ of them were females,

Cross tabulation between positive gastritis patients to $H$. pylori organism gender and Amoxicillin antibiotic sensitivity with risk estimate between males and females was shown in (Table 4). In respect to gender, $81.8 \%$ of the males were sensitive to Amoxicillin antibiotics and $18.2 \%$ of them were resistant.

Where, $70.6 \%$ of the females were sensitive to Amoxicillin and $29.4 \%$ of them were resistant. In respect to the Amoxicillin antibiotic sensitivity itself, $42.9 \%$ of the sensitive to Amoxicillin were males and $57.1 \%$ of them were females. While, $28.6 \%$ of the resistant to Amoxicillin were males and $71.4 \%$ of them were females.

Cross tabulation between positive gastritis patients to $H$. pylori organism gender and Furazolidone antibiotic sensitivity with risk estimate between males and females was shown in (Table 5).

In respect to gender, $100 \%$ of the males were sensitive to Furazolidone antibiotics and $0.0 \%$ of them were resistant. Where, $76.5 \%$ of the females were sensitive to Furazolidone and $23.5 \%$ of them were resistant, (In respect to the Furazolidone antibiotic sensitivity itself, $0.0 \%$ of the resistant to Furazolidone were males and $100 \%$ of them were females. While, $45.8 \%$ of the sensitive to Furazolidone were males and $54.2 \%$ of them were females. 
Table.1 Cross tabulation of positive gastritis patients to H. pylori organism between Clarithromycin antibiotic sensitivity and Gender with risk estimate between them

\begin{tabular}{|ll|r|r|c|}
\hline & & \multicolumn{2}{|c|}{ Clarithromycin } & \multirow{2}{*}{ P } \\
\cline { 2 - 4 } & Sensitive & Resistance & P \\
\hline Gender Male Count & 10 & 1 & 0.664 \\
& $\%$ within Gender & $90.9 \%$ & $9.1 \%$ & \\
& $\%$ within Clarithromycin & $40.0 \%$ & $33.3 \%$ & \\
\cline { 2 - 4 } Female Count & 15 & 2 & \\
& $\%$ within Gender & $88.2 \%$ & $11.8 \%$ & \\
\% within Clarithromycin & $60.0 \%$ & $66.7 \%$ & \\
\hline
\end{tabular}

Table. 2 Cross tabulation of positive gastritis patients to $H$. pylori organism between Metronidazole antibiotic sensitivity and Gender with risk estimate between them

\begin{tabular}{|ll|r|r|c|}
\hline & & \multicolumn{2}{|c|}{ Metronidazole } & \multirow{2}{*}{ P } \\
\cline { 3 - 4 } & & Sensitive & Resistance & \multicolumn{1}{|c|}{ P } \\
\hline Gender & Male $\quad$ Count & 10 & 1 & 0.664 \\
& & $90.9 \%$ & $9.1 \%$ & \\
& \% within Gender & $40.0 \%$ & $33.3 \%$ & \\
\cline { 2 - 5 } & Female within Metronidazole & 15 & 2 & \\
& Count & $88.2 \%$ & $11.8 \%$ & \\
& \% within Gender & $60.0 \%$ & $66.7 \%$ & \\
\hline
\end{tabular}

Table.3 Cross tabulation of positive gastritis patients to $H$. pylori organism between Tetracycline antibiotic sensitivity and Gender with risk estimate between them

\begin{tabular}{|ll|r|r|r|}
\hline \multirow{2}{*}{} & & \multicolumn{2}{|c|}{ Tetracycline } & \multirow{2}{*}{ P } \\
\cline { 2 - 4 } & Sensitive & Resistance & P \\
\hline \multirow{2}{*}{ Gender } & 9 & 2 & 0.518 \\
& \% within Gender & $81.8 \%$ & $18.2 \%$ & \\
\cline { 2 - 4 } Female & $37.5 \%$ & $50.0 \%$ & \\
& Count & 15 & 2 & \\
& $\%$ within Tetracycline & $88.2 \%$ & $11.8 \%$ & \\
& $62.5 \%$ & $50.0 \%$ & \\
\hline
\end{tabular}


Table.4 Cross tabulation of positive gastritis patients to $H$. pylori organism between Amoxicillin antibiotic sensitivity and Gender with risk estimate between them

\begin{tabular}{|ll|r|r|r|}
\hline & & \multicolumn{2}{|c|}{ Amoxicillin } & \multirow{2}{*}{ Count } \\
\cline { 2 - 4 } & Sensitive & Resistance & P \\
\hline Gender & 9 & 2 & 0.419 \\
& $\%$ within Gender & $81.8 \%$ & $18.2 \%$ & \\
\cline { 2 - 4 } Female within Amoxicillin & $42.9 \%$ & $28.6 \%$ & \\
& Count & 12 & 5 & \\
& $\%$ within Gender & $70.6 \%$ & $29.4 \%$ & \\
& $\%$ within Amoxicillin & $57.1 \%$ & $71.4 \%$ & \\
\hline
\end{tabular}

Table.5 Cross tabulation of positive gastritis patients to $H$. pylori organism between Furazolidone antibiotic sensitivity and Gender with risk estimate between them

\begin{tabular}{|ll|r|r|r|}
\hline & & \multicolumn{2}{|c|}{ Furazolidone } & \multirow{2}{*}{} \\
\cline { 3 - 4 } & & Sensitive & Resistance & $\mathrm{P}$ \\
\hline Gender & 11 & 0 & 0.088 \\
& \%ale $\quad$ Count & $100.0 \%$ & $0.0 \%$ & \\
& $\%$ within Gender & $45.8 \%$ & $0.0 \%$ & \\
\cline { 2 - 4 } & Female Count & 13 & 4 & \\
\% within Gender & $76.5 \%$ & $23.5 \%$ & \\
\% within Furazolidone & $54.2 \%$ & $100.0 \%$ & \\
\hline
\end{tabular}

Chronic infection caused by Helicobacter pylori (H. pylori) is associated with chronic gastritis, peptic ulcer disease, and gastric cancer. Eradication of $H$. pylori reduces morbidity of chronic gastritis and incidence of gastric cancer in high-risk population. A combination of different antibiotics was mostly used in $\mathrm{H}$ pylori eradication. Chon, et al., (2013) Eradication of $H$. pylori likely has a beneficial effect in preventing the development of subsequent gastric dysplasia, a premalignant lesion of gastric cancer, after endoscopic resection. While dual therapy is comparable to recommended rescue therapies for clarithromycin-resistant $H$. pylori (Gao, et al., 2016), Alboraie et al., (2015), found that bismuth-based quadruple therapy is more effective as a first-line therapy than clarithromycin-based triple therapy for eradicating $H$. pylori in patients with $H$. pylori-related chronic gastritis. As standard triple therapies currently fail to cure $80 \%$ of $H$. pylori infections in most populations due to an increased antibiotic resistance, especially to clarithromycin (Tongtawee et al., 2015) therefore the use of clarithromycinbased triple therapy is not advisable as an empiric first-line regimen for $H$. pylori eradication in different world parts. In the present study different antibiotic were used to 
test $H$ pylori response, they were Clarithromycin, Metronidazole, Tetracycline, Amoxicillin and Furazolidone. The sensitivity of each antibiotic was calculated and statically analyzed.

H pylori response to both Clarithromycin and Metronidazole antibiotic sensitivity was giving the same figures. In respect to gender, $90.9 \%$ of males and $88.2 \%$ of females were sensitive to both antibiotics. Tetracycline antibiotic sensitivity was showing that $81.8 \%$ of the males and $88.2 \%$ of the females were sensitive to Tetracycline antibiotics. Amoxicillin antibiotic sensitivity was showing that, $81.8 \%$ of the males and $70.6 \%$ of the females were sensitive to Amoxicillin antibiotics. Finally Furazolidone antibiotic sensitivity was showing that, $100 \%$ of the males and $76.5 \%$ of the females were sensitive to Furazolidone antibiotics.

It may be concluded that $\mathrm{Hp}$ is dependent on temporal hypoacidity or an acidity for its primary infection, but acidity to survive for a long time. Hp infection in the antral mucosa causes duodenal ulcers induced by increased gastric acid secretion secondary to slight increased gastrin release from the $G$ cells, probably due to $\mathrm{NH} 3$ production provoked by urease. When infecting the oxyntic mucosa causing inflammation, the functions (mucous and $\mathrm{HCO}_{3}-$ production) of the superficial cells are reduced, predisposing for gastric peptic ulcer. Long-term infection of the oxyntic mucosa causes atrophy and marked reduced gastric acid secretion, leading to gastric hypoacidity. HP does not survive in a too acidic (patients with gastrinoma) or in an anacidic stomach. The interactions between $\mathrm{Hp}$ and the stomach are very complex, but we now understand the pathogenesis of most of the diseases in the stomach and duodenum, since Hp plays a central role in most of these conditions. A combination of different antibiotics (Clarithromycin, Metronidazole,
Tetracycline, Amoxicillin and Furazolidone) was mostly used in $\mathrm{H}$ pylori eradication. Eradication of $H$. pylori likely has a beneficial effect in preventing the development of subsequent gastric dysplasia, a premalignant lesion of gastric Ulcer.

\section{References}

Alboraie M, Saad M, Al-Ali J, Malik M, Asem N, Schmidt I, Alfadhli AA (2015): Quadruple therapy versus standard triple therapy for eradication of Helicobacter pylori in Kuwait. Arab J Gastroenterol. Sep-Dec; 16(3-4): 131-5.

Alm, R. A., Bina, J., Andrews, B. M., Doig, P., Hancock, R. E. and Trust, T. J. (2000): Comparative genomics of Helicobacter pylori: analysis of the outer membrane protein families. Infect Immun68, 41554168

Boyanova, L (editor) (2011): Helicobacter pylori. Caister Academic Press. ISBN 978-1904455-84-4

Costa, A.M., Leite, M., Seruca, R., and Figueiredo, C. (2013). Adherens junctions as targets of microorganisms: a focus on Helicobacter pylori. FEBSLett. 587, 259265.

De Medina S, Fermín; Romero-Calvo, Isabel; Mascaraque, Cristina; Martínez-Augustin, Olga (2014): "Intestinal inflammation and mucosal barrier function". Inflammatory Bowel Diseases. 20 (12): 2394-2404.

Edwards, N.J., Monteiro, M.A., Faller, G., Walsh, E.J., Moran, A.P., Roberts, I.S., High, N.J. (2000): Lewis X structures in the $\mathrm{O}$ antigen side-chain promote adhesion of Helicobacter pylori to the gastric epithelium. Mol. Microbiol., 35, 15301539.

Fox, J. G. (2002): The non- $H$. pylori helicobacters: their expanding role in gastrointestinal and systemic diseases. Gut 50:273-283.

Gao CP, Zhou ZHOU, Jia Zhen WANG, Sheng Xi HAN, Liang Ping LI, Hong LU (2016): Efficacy and safety of high dose dual therapy for Helicobacter pylori rescue therapy: A systematic review and meta- 
analysis. J Dig Dis. Dec 15.

Goh, K.L., Chan, W.K., Shiota, S., and Yamaoka, Y.(2011): Epidemiology of Helicobacter pylori infection and public healthimplications. Helicobacter 16 (Suppl.1), 1-9.

Helge L. Waldum, Per M. Kleveland and Øystein F. Sørdal(2016): Helicobacter pylori and gastric acid: an intimate and reciprocal relationship. Ther Adv Gastroenterol, Vol. 9(6) 836-844.

Hosseini, E., Poursina, F., deWiele, T.V., Safaei, H.G., and Adibi, P. (2012). Helicobacter pylori in Iran: a systematic review on the association of genotypes and gastro duodenal diseases. J.Res.Med.Sci. 17,280 292.

Kist M. (2006): Impact of German National Reference Centres on monitoring of antibiotic resistance. Int $\mathbf{J}$ Med Microbiol; 296(supplement 41): 55e61.

Martínez, L.E., Hardcastle, J.M., Wang,J., Pincus, Z., Tsang, J., Hoover, T.R., etal.(2016). Helicobacter pylori strains vary cell shape and flagellum number to maintain robust motility in viscous environments. Mol.Microbiol. 99,88-110.

Muotiala, A., Helander, I.M., Pyhala, L., Kosunen, T.U., Moran, A.P. (1992): Low biological activity of Helicobacter pylori lipopolysaccharide. Infect. Immun., 60, 1714-1716.

Murakami, K., Sakurai, Y., Shiino, M., Funao, N., Nishimura, A. and Asaka, M. (2016): Vonoprazan, a novel potassium-competitive acid blocker, as a component of first-line and second-line triple therapy for Helicobacter pylori eradication: a phase III, randomised, double-blind study. Gut 65: 1439-1446.

Nilsson HO, Blom J, Abu-Al-Soud W, Ljungh A A, Andersen LP, Wadström T. (2002):Effect of cold starvation, acid stress, and nutrients on metabolic activity of Helicobacter pylori. Appl Environ Microbiol; 68: 11-19 [PMID: 11772603

Olson JW, Maier RJ (2002): "Molecular hydrogen as an energy source for Helicobacter pylori". Science. 298 (5599): 1788-90.

O'Toole PW, Lane MC, Porwollik S.(2000): Helicobacter

pylori motility. Microbes Infect;2:12071214.

Scott, D., Weeks, D., Hong, C., Postius, S., Melchers, K. and Sachs, G. (1998): The role of internal urease in acid resistance of Helicobacter pylori. Gastroenterology 114: 58-70.

Tie J, Zhang X and Fan D (2016): Epigenetic roles in the malignant transformation of gastric mucosal cells. Cell. Mol. Life Sci. 73:4599-4610.

Tongtawee T, Chavaboon Dechsukhum, Likit Matrakool, Sukij Panpimanmas, Ryan A Loyd, Soraya J Kaewpitoon, Natthawut Kaewpitoon(2015): High Prevalence of Helicobacter pylori Resistance to Clarithromycin: a Hospital-Based CrossSectional Study in Nakhon Ratchasima Province, Northeast of Thailand. Asian Pac $J$ Cancer Prev, 16 (18), 8281-8285.

Yamaoka, Yoshio (2008): Helicobacter pylori: Molecular Genetics and Cellular Biology. Caister Academic Pr.

\section{How to cite this article:}

Haitham Refaay Mustafa Elshiekh, Amr Mohamed Hassan Elrabat, Abd EL Mohsen E. EL desoky and Mahmoud Mohammed Zaky. 2017. Antibiotic Sensitivity to Helicobacter pylori Growth. Int.J.Curr.Microbiol.App.Sci. 6(12): 3999-4006. doi: https://doi.org/10.20546/ijcmas.2017.612.460 